\title{
A IMPORTÂNCIA DA INVESTIGAÇÃO NARRATIVA NA EDUCAÇÃO
}

\author{
AmANDA Oliveira RABElo*
}

\begin{abstract}
RESUMO: Este artigo apresenta uma análise da importância da investigação narrativa para pesquisar os cotidianos educacionais. Descrevemos a relevância deste tipo de investigação como contribuição à articulação da teoria com a prática, do social com o individual. Também ressaltamos as características deste tipo de investigação, diferenciando duas formas de cognição (narrativa e paradigmática) que proporcionaram a distinção de duas formas de análise dentro das investigações narrativas. Através da descrição destas formas apontamos os pontos positivos e negativos de cada uma delas, mostrando que os dois tipos de investigação não são dicotômicos, podem ser complementares e têm muito a contribuir às investigações educacionais. Enfim, para contornar as dúvidas que marcam qualquer investigação, é imprescindível considerar todas as questões, inclusive as práticas, e intensificar os cuidados na busca das bases narrativas para as investigações na educação.
\end{abstract}

Palavras-chave: Investigação narrativa. Teoria. Método.

\section{THE IMPORTANCE OF NARRATIVE RESEARCH IN EDUCATION}

ABSTRACT: This paper analyzes the importance of research narrative to investigate day-to-day education. It describes the relevance of such research as a contribution to linking theory and practice, the social and the individual. After highlighting the characteristics of this kind of research, it distinguishes between two forms (narrative and paradigmatic) of cognition and, thus, two forms of analysis within narrative research. It then describes both, pointing out their positive and negative sides to shows that they can be complementary (non-dichotomous) and have much to contribute to educational research. Finally, to bypass the doubts that mark any investigation, all the issues, including practices, must be considered and the care in search of narrative bases to investigate education must be intensified.

Key words: Narrative research. Theory. Method.

\section{L'IMPORTANCE DE LA RECHERCHE NARRATIVE DANS L'ÉDUCATION}

RÉSUMÉ: Cet article présente une analyse de l'importance de la recherche narrative pour faire analyser les quotidiens éducatifs. Il décrit la pertinence de ce type d'investigations comme contribution à l'articulation de la théorie et de la pratique, du social et de l'individuel. Il souligne également les caractéristiques

Pós-doutoranda em Ciências da Educação na Universidade de Coimbra e professora da Escola Superior de Educação Almeida Garrett (ESEAG, Lisboa). Projeto de investigação financiado pela Fundação para a Ciência e a Tecnologia (FCT). E-mail: amandaorabelo@hotmail.com 
de ce type d'examen et distingue deux formes de cognition (narrative et paradigmatique) qui permettent la discerner deux formes d'analyse dans les recherches narratives. Après avoir décrit ces deux formes, il désigne les points positifs et négatifs de chacune, montrant que ces deux types de recherche ne sont pas dichotomiques, mais peuvent être complémentaires et ont beaucoup à apporter aux investigations sur l'éducation. Finalement, pour contourner les doutes marquant toute recherche, il est indispensable de considérer toutes ces questions, y compris les pratiques, et d'intensifier les précautions en quête des bases narratives pour les recherches en éducation.

Mots-clefs: Recherche narrative. Théorie. Méthode.

\section{Introdução}

$\mathrm{D}$

urante muito tempo o que se relacionava com a prática foi menosprezado frente à "ciência". Hoje, entretanto, a relevância das práticas, e da sua articulação com a teoria, motiva o trabalho e a atenção de muitos autores que fazem uso de alguns tipos de investigações da prática no campo educacional. Nosso foco de discussão, neste artigo, é justamente sobre uma modalidade de pesquisa que valoriza a exposição dos pensamentos dos indivíduos acerca da sua visão de mundo: a investigação narrativa.

O professor não é só um trabalhador na sociedade, ele pode ser um formador de opiniões e um instigador de discussões. Dessa forma, a sua tomada de posição interfere não só na sua vida, mas na própria formação da sociedade. Por isso, exaltamos a necessidade de que ele tenha conscientização na sua atuação/escolha profissional e objetivamos incitar a integração das perspectivas individuais e sociais na análise dos relatos. Isso porque, apesar de difícil, não é impossível ultrapassar as determinações. As pessoas não estão determinadas a priori, nem são responsáveis pelo seu fracasso ou sucesso: o social interfere nas oportunidades que surgem na vida, mas existe algo de individual que nos permite ter razões próprias que podem ir além dos imperativos sociais.

\section{Narrativa: o conceito que palpita a complexidade da prática}

A narrativa permite compreender a complexidade das estórias contadas pelos indivíduos sobre os conflitos e dilemas de suas vidas. Bolívar (2002) entende-a como a qualidade estruturada da experiência percebida e vista como um relato, captando a riqueza e os detalhes dos significados nos assuntos humanos, tendo como base as evidências do mundo da vida. Reconstrói-se a experiência refletindo sobre o vivido e dando significado ao sucedido.

Para Brockmeier e Harré (2003), a utilização geral do termo narrativa denomina um conjunto de estruturas lingüísticas e psicológicas transmitidas cultural e 
historicamente, delimitadas pelo domínio individual de cada um, mas combinadas com as técnicas sócio-comunicativas, bem como a linguagem, adquiridas socialmente.

Estes autores afirmam que as palavras nunca são proferidas apenas pelo indivíduo, elas são articuladas a partir de várias narrativas particulares, a partir de pontos de vista específicos, determinadas em certo contexto e por certas vozes. As narrativas seriam um modo específico de construção e constituição da realidade que compõe um conjunto de regras do que é aceito, ou não, em determinada cultura.

Jerome Bruner é um dos autores mais importantes para a compreensão das narrativas e, conseqüentemente, para o surgimento da investigação narrativa. O autor (1990) baseia-se em alguns pressupostos da psicologia cultural, principalmente na necessidade de enveredarmos por uma abordagem mais histórica e interpretativa. Contudo, vai além destes pressupostos e apresenta como a "realidade" é construída: pela narrativa, que media a própria experiência e configura a construção social da realidade, o que também inclui a subjetividade, sempre relacionada com o discurso comunicativo.

Para Bruner (1990), as influências que dominam as transações da vida cotidiana e tornam o significado público e partilhado na participação cultural (a "psicologia comum") têm um princípio organizador mais narrativo do que conceitual, pois a narrativa organiza a experiência. Quando as coisas "são como devem ser" as explicações narrativas da "psicologia comum" são desnecessárias, ou seja, o usual da condição humana é revestido de legitimidade e os desvios da norma são verificados; quando há uma exceção, o relato precisa de uma razão, de uma explicação. Contar uma estória é assumir uma posição moral.

Lyotard (1989) também descreve a narração como a forma por excelência do saber das classes populares, da cultura de um povo. Ela obedece às regras fixadas pela pragmática, determinando o que é preciso dizer para ser ouvido, escutar para poder falar e o que desempenhar para ser objeto de uma narrativa. O que se transmite com as narrativas é o grupo de regras pragmáticas que constitui o vínculo social, encontrando a matéria desse vínculo não só na significação dos relatos, mas no próprio ato de sua narração, com a utilização do ritmo, que compassa o tempo, e da temporalização, que visa o não esquecer.

Para Bruner (op. cit.), nossa propensão para organizar a experiência em forma de narrativa não serve somente para conservar e elaborar uma tradição, mas para interpretar e "melhorar" o que se passou, promovendo uma nova forma de contar. A narrativa é um veículo da "psicologia comum", reitera as normas da sociedade, pode ensinar, conservar a memória ou alterar o passado, não é realizada nem para manter o social, nem para assegurar a "lembrança" individual. A estória é contada a partir de um conjunto de prismas pessoais. Dessa forma, podem existir várias versões, pois há uma vertente inevitavelmente humana para a instituição de sentido. 
Nesse sentido, Gudmundsdóttir (2001) destaca que a ação e o significado deixam traços no espaço social e transformam a atividade humana através da memória coletiva proferida nas instituições. A ação mediada vai além da situação inicial e torna-se relevante em outros contextos. Dessa maneira, os significados vão além dos pretendidos pela pessoa envolvida na ação original. Na construção de uma narrativa da prática os investigadores são sempre intérpretes, pois entre as experiências do campo está o esforço por fazer sentido e descrever estas experiências.

Diante destas constatações, preconizamos que tanto o aspecto social quanto o individual motivam a memorização e a narrativa, mas as instituições também tornamse importantes na esquematização da memória/narração, pois, como Bruner (1990, p. 62) explica, a nossa experiência e memória do mundo social são estruturadas por concepções profundamente interiorizadas e narrativizadas da psicologia comum e também por instituições elaboradas historicamente por certa cultura a apoiar e reforçar.

Na mesma linha, Lyotard (1989) e Foucault (1979) salientam as instituições como forma de imposição de limites para o que pode ser dito e de que maneira. A disciplinação é um dos principais encargos institucionais, mas as instituições também estão submetidas a estes jogos, há uma disputa de estratégias de linguagem conduzidas dentro e fora do ambiente institucional.

A narrativa está presente nas instituições e nas relações sociais, assim também é percebida como instrumento de disciplinação e poder. Gudmundsdóttir (2001) argumenta que o fato da fala estar interconectada intimamente com a cultura faz com que ela não exista de forma totalmente individual, pois toda a voz se insere no contexto de muitas vozes situadas cultural e singularmente. As multivozes da sociedade trazem influências e uma bagagem invisível das ideologias e questões éticas da nossa cultura. As narrativas podem ser utilizadas de forma emancipatória, ou reproduzindo as estruturas hierárquicas da nossa cultura.

Compreendemos com Foucault (1979) que nem o poder nem as resistências a ele têm lugar definido, mesmo as ações emancipatórias são partes de uma luta que se exerce dentro das relações de poder, pois o indivíduo é uma produção do poder e do saber, não existindo uma individualidade anterior que se torna dominada pelo poder. Os saberes estão intimamente interligados ao poder que, como prática social, é constituído historicamente. Contudo, o poder não existe, ele se exerce. O que existe são práticas ou relações de poder que produzem individualidades, não por coerção, mas por inserção do indivíduo desde seu nascimento dentro de um mundo onde o poder atua. ${ }^{1}$

Ainda neste sentido, Gudmundsdóttir (op. cit.) define a subjetividade do sujeito como não-unitária, pois a linguagem, as questões éticas, os relacionamentos, as interações sociais e as experiências são centrais. O sujeito unitário é um mito que demonstra algumas dominações sociais. Ou seja, o fato de estarmos em contato com 
o social, e com as pessoas da sociedade, leva-nos a adquirir não só uma subjetividade não-unitária, mas uma memória que, de acordo com Bruner (op. cit.), é lembrada pela relação dialógica que tivemos com uma pessoa com quem mantivemos contato. Assim, o que nos faz lembrar e organizar a memória é a dialética entre os indivíduos, os grupos, as instituições e as relações sociais do meio.

Berger e Luckman (1985) apreciam que, para além da importância do afeto e da identificação, a linguagem tem que ser um conteúdo interiorizado, acima de tudo, na socialização primária. ${ }^{2}$ Ela diferencia (e legitima) a identidade do indivíduo, ou seja, ela institui significados aos papéis e interpretações, construindo o primeiro mundo do indivíduo que deve ser considerado real.

A narrativa não é só estrutura de enredo nem historicidade. Para Bruner (1990), é uma forma de utilizar a linguagem. O significado simbólico depende da interiorização e utilização do seu sistema de signos como um interpretante e, por isso, precisa-se da interação com as pessoas. O domínio inicial da língua só pode advir da participação na comunicação.

Como conseqüência da necessidade de relação dialógica, adquire-se a narração da experiência naturalmente com a aprendizagem de uma língua. Gudmundsdóttir (2001) explica que, gradualmente, os povos em todas as culturas desenvolvem intersubjetivamente maneiras distintas de saber, compreender e perceber sua realidade física e social compartilhada. A narrativa funciona como um "guião" para ajudar-nos a fazer sentido. Utilizamos-na constantemente porque o social se apresenta a nós como uma narrativa e podemos aplicá-la seletivamente a quase todos os aspectos de nossas vidas.

Viver numa cultura é viver num conflito de interesses. Uma das maiores formas de preservar a paz é o dom humano de explicar as circunstâncias atenuantes. Viver numa cultura é estar entrosado em várias histórias que, na maioria das vezes, não representam um consenso. A perspectiva interpretativa de Bruner (1990) nos explica que o consenso não é o mais importante de uma cultura - apesar de ser necessário e de embasar as visões de mundo de quem pertence à determinada cultura -, mas o relacionamento e as disputas entre diferentes posturas de construção da realidade. A narrativa é um dos dispositivos sempre utilizados nestas lutas para manter a sua percepção de mundo. Até o "poder" faz uso dela.

Bruner assinala que o colapso de uma cultura acontece quando não há mais consenso entre o habitual e o canônico na vida, quando há uma superespecialização retórica da narrativa ou um empobrecimento dos recursos narrativos, que não quer dizer que a experiência não se dê mais na forma de narrativa, mas que a história "negativa" acaba por dominar a vida diária, ao ponto que outra história parece não ser possível. 
Quanto às discussões da ligação da narrativa com o pessoal e o social, Bruner (op. cit.) reavalia o conceito de "si mesmo", muito utilizado na psicologia, afirmando que este não estaria localizado somente na consciência privada, mas também numa situação histórico-cultural. A cultura é reformulada pelo indivíduo por meio da "reflexividade" ${ }^{\prime 3}$ que a nossa capacidade narrativa oferece, além de uma capacidade intelectual de "visionar alternativas", concebendo outras maneiras de ser, de agir, de falar.

Estas mudanças na percepção do nosso passado são observadas de forma mais clara nas investigações narrativas, pois no ato de relatar a reflexividade é ativada, até mesmo porque ao interagir com outra pessoa o sujeito tem a possibilidade de tentar esclarecer os seus motivos e modos de ser. Dessa forma, estes estudos compreendem que o entendimento de "si mesmo" se realiza somente com um esforço interpretativo. O "si mesmo" é uma narração, pois estamos sempre a contar histórias sobre nós a nós próprios, recuperamos uma memória criando uma nova narrativa. As narrativas obtidas por este estudo contêm muito deste esforço de elucidar, criar e recriar explicações para formas de agir e de pensar.

Polkinghorne (1988) diz que o nosso próprio autoconceito é formado por uma configuração narrativa, nossas estórias são revistas constantemente, à medida que novos eventos se acrescentam às nossas vidas. $\mathrm{O}$ "si mesmo" não é algo estático ou uma substância, mas uma configuração de eventos pessoais numa unidade narrativa que inclui não só o que fomos, mas também antecipações do que seremos.

Estas ponderações nos lembram que as narrativas proporcionadas pelos entrevistados são totalmente dependentes do contexto em que os mesmos se encontram (e também do objetivo com que deram a entrevista). As mesmas poderiam ser totalmente diferentes se entrevistássemos anos antes ou anos depois, quem sabe até mesmo na semana seguinte. ${ }^{4}$ Enfim, as construções da sua singularidade dependem do contexto social e histórico, as contribuições são somadas e reformuladas. Para entender as regras em que os seres humanos se fundam, ao criarem significados em contextos prático-culturais, devemos indagar e interpretar o que a pessoa faz ou tenta fazer em determinada situação e local.

A narrativa não é uma construção livre, ela conta os significados que a pessoa constrói para o "si mesmo". Para Bruner (1990), a autobiografia não é um registro, mas uma narração do que se pensa que se fez, em que circunstâncias, de que formas, por que razões. É um relato feito no presente por um narrador, sobre o processo de construção de um protagonista que tem o seu nome e existiu num passado, desembocando a história no presente, onde o protagonista se une com o narrador.

Então, o narrador não pode falar de si no passado? Pode, mas este de quem ele fala não representa mais o que ele é no presente, ele aprende e reconstrói a sua forma de pensar. Por isso, muitas pessoas dizem que não fariam mais o que 
fizeram. O arrependimento é uma interpretação do passado. Contudo, nem só de arrependimentos vivem os relatos. Muitas vezes, o indivíduo não tem certa motivação para o seu ato, mas ele depois a encontra e justifica as suas ações por estas novas descobertas.

Consideramos o entrevistado como este narrador que busca no "ato de contar" as explicações que muitas vezes ele queria ter tido ou que só descobriu depois. Com esta elucidação demarcamos que uma narrativa não é a verdade tal como aconteceu, mas uma interpretação da pessoa que também será por nós interpretada. Só mediante a interpretação podemos fazer jus ao mundo cultural.

A "psicologia comum" é um exercício da narrativa e do contar histórias que se suporta por uma poderosa estrutura de cultura narrativa. $\mathrm{O}$ "si mesmo", ou "eu", não é isolado na consciência de cada um, mas interpessoalmente distribuído, vai buscar significado nas circunstâncias históricas que dão forma à cultura (Bruner, 1990).

Algumas versões pessoais do "si mesmo" podem ser preferidas a outras, possivelmente por causa das concepções "oficiais", ou "forçadas", serem utilizadas para estabelecer um controle político ou hegemônico de um grupo sobre o outro. Muitas pesquisas narrativas destacam esse controle, por exemplo, do domínio das concepções machistas na cultura ocidental frente às biografias e maneiras de contar das mulheres.

Entretanto, o controle pode ser alvo de resistências. Gudmundsdóttir (2001) exprime que uma narrativa de "si mesmo" pode tornar-se emancipatória, quando vai além do mito da "subjetividade unificada" e permite a validação do conflito como uma fonte em que os grupos minoritários tornam-se fortes e falam de suas próprias experiências.

Podemos concluir que nossa individualidade não contém uma identidade imutável, mas é algo que construímos socialmente no decorrer de nossas vidas e que muda constantemente. As narrações de nós mesmos nos ajudam a construir nosso significado, tanto para cada um quanto para os outros na sociedade.

As investigações que utilizam narrativas tornam possível o relato das experiências não só dos legitimados, mas das minorias, possibilitando que se ouçam outras vozes, além das que respondem pelas deliberações. A potencialidade destas novas vozes pode mostrar que as discriminações e papéis são provocados por forças sociais, mas que pode haver uma resistência a estas determinações.

\section{A narrativa como investigação}

É por intermédio das perspectivas franqueadas por um posicionamento crítico avesso às antinomias que podemos situar as narrativas como um elo entre o prático e 
o teórico. No pensamento acadêmico a separação das formas de conhecimentos em cognitivo versus emocional tem recebido um novo significado. Um dos responsáveis por esta mudança também foi Jerome Bruner, que argumenta que o conhecimento narrativo é mais do que mera expressão de emoção, sendo uma forma legitimada de raciocínio de saber.

Ele propõe dois tipos de cognição ou racionalidade (Bruner, 1986), dois modos de pensamentos que se completam. Estes não representam uma oposição, mas sim a complementaridade. Para capturar a rica diversidade da cognição não se pode ignorar nenhum destes dois conhecimentos. É preciso analisá-los para compreender as diferentes maneiras de se lidar com a experiência. Cada maneira de conhecer tem princípios e critérios específicos, diferem nos procedimentos de verificação e na forma de argumentação. Os dois tipos de cognição descritos por Bruner (op. cit.) são:

- Paradigmático: é o conhecimento tomado por regras e prescrições, onde o saber só pode existir se for proposital, formal e científico. Este modelo é influenciado pelos métodos positivistas.

- Narrativo: é o conhecimento prático, abarca o saber popular construído de modo biográfico-narrativo. Os métodos utilizados por este conhecimento são hermenêuticos, interpretativos e narrativos. Os discursos são apresentados com sentimentos, ações, estórias e imagens.

O "conhecimento paradigmático" classifica os indivíduos, anulando as diferenças individuais, e baseia-se na lógica científica, em um sistema matemático de explicação e descrição. Ele emprega a conceitualização ou categorização como operações para que sejam estabelecidas as categorias, idealizadas e relatadas para formar um sistema pelo qual as proposições gerais são extraídas dos contextos particulares. A aplicação deste conhecimento leva à construção de uma teoria baseada em análises, provas lógicas e descobertas empíricas guiadas pelo raciocínio acerca de uma hipótese, buscando sempre transcender as particularidades.

Polkinghorne (1995) ressalta que o importante na "cognição paradigmática" é classificar uma instância particular como categoria, ou conceito, definindo-a como um ponto de características comuns às investigações. Os conceitos gerais podem incluir subconceitos ou subcategorias e em cada um determina-se um atributo peculiar chamado diferença específica. $\mathrm{O}$ "conhecimento paradigmático" foca no que é comum entre as ações, é mantido por palavras individuais que nomeiam um conceito.

De modo contrário, a "cognição narrativa" parte do pressuposto de que as ações são únicas, assim não há como exibi-las em definições, categorias ou proposições abstratas. O conhecimento narrativo é dirigido ao entendimento da ação humana e é mantido por estórias enredadas que retêm a complexidade da situação, 
enfatizando o particular e as características especiais de cada ação, possibilitando compreender como os indivíduos dão sentido ao que fazem. Por isso, não deve ser reduzido a um conjunto de categorias abstratas ou gerais que anulem sua singularidade. ${ }^{5}$

O efeito cumulativo do "raciocínio narrativo" é uma coleção de casos individuais em que o pensamento move de caso para caso, em vez de casos para generalização. Essa coleção de casos providencia uma base para entender novas ações por meio da analogia. O entendimento analógico reconhece a improvisação e mudança que compõem a variabilidade flexível do comportamento humano.

Bolívar, Domingo e Fernández (2001) apresentam a investigação narrativobiográfica como um enfoque próprio ou perspectiva específica (não é um método e vai além de uma estratégia metodológica ${ }^{6}$. Tem chegado a ser um ramo da investigação interpretativa que comparte alguns dos princípios metodológicos da investigação qualitativa, ${ }^{7}$ mas que introduz algumas fissuras na investigação qualitativa habitual (como o fato de que a experiência vivida não é algo a captar, mas criada no próprio processo investigativo).

A investigação narrativa baseia-se em uma epistemologia construtivista e interpretativa e tem como pressupostos o entendimento: que a linguagem media a ação; que a narrativa é a estrutura central do modo como os humanos constroem os sentidos, ou seja, o curso de vida e a identidade pessoal são vividos como uma narração; que a trama argumental configura o relato narrativo; que temporalidade e narração formam um todo (o tempo constitui significado); que as narrativas culturais e individuais estão interligadas (Bolívar, Domingo \& Fernández, op. cit.).

Nela, as prescrições de uma metodologia (as "receitas de cozinha") não levam muito longe e não asseguram nada, pois em uma perspectiva mais interpretativa o significado dos agentes se converte no foco central da investigação e abarca-se a dimensão emotiva da experiência, a complexidade, relações e singularidade de cada ação (que não é possível de ser rigorosamente controlada). Por isso, a investigação narrativa é um enfoque interdisciplinar (envolve várias questões), um novo campo de investigação, reorganizado a partir de fundamentos filosóficos e epistemológicos próprios e que compreende qualquer forma de reflexão oral ou escrita que empregam a experiência pessoal. Mas como o relato não fala por si mesmo, deve ser organizado e conceitualizado, e é dependente da interação social estabelecida entre informante e investigador (idem, ibid.).

Os relatos narrativos podem apresentar-se de várias formas (filmes, balé, contagens orais, entre outros) e também podem receber a contribuição de várias técnicas, ${ }^{8}$ além da entrevista gravada e transcrita, ou seja, não exclui outros meios escritos. ${ }^{9}$ No entanto, em qualquer investigação narrativa estes são complementares à entrevista, pois a oralidade é a fonte mais importante e, por isso, a entrevista 
narrativa ${ }^{10}$ é essencial, transformando-as em formato escrito através de transcrições. O seu resultado é uma estória apresentada de várias maneiras ${ }^{11}$ (Polkinghorne, 1995; Bolívar, Domingo \& Fernández, 2001).

A distinção efetuada por Bruner entre "cognição narrativa e cognição paradigmática" proporcionou a reflexão de alguns autores, distinguindo duas formas de análise nas investigações narrativas. De acordo com Polkinghorne (1995), ambas contêm princípios gerais da investigação narrativa, mas o fazem de forma diferente:

- A análise narrativa paradigmática, ou análise de narrativa, baseia-se em dados consistidos de narrativas ou estórias, mas cujas análises produzem tipologias ou categorias paradigmáticas, sendo utilizados como elementos ou base comum de dados. Coletam-se relatos estoriados para os dados, usando um processo que identifica aspectos como instâncias de categorias. A investigação narrativa do tipo paradigmático produz conhecimento de conceitos.

- A análise narrativa, propriamente dita, opera com elementos combinados entre uma estória "enredada", coletando descrições de eventos, acontecimentos, ações, cujas análises produzem estórias (por exemplo: biografias, estórias, estudos de caso). A análise narrativa produz conhecimento de situações particulares.

Bolívar (2002) explica que a razão paradigmática encontra-se presente tanto em investigações quantitativas quanto em qualitativas. A diferença está na definição das categorias antes da recolha de dados nas investigações quantitativas de análise narrativa paradigmática e, a posteriori, na investigação qualitativa (sendo induzidas ou emergindo dos dados). Dessa forma, Bolívar, Domingo e Fernández (2001) demarcam que, no fundo, seguem a mesma lógica do questionário: tratamento qualitativo de material qualitativo; empregam com fim ilustrativo partes selecionadas das entrevistas.

A análise de narrativa paradigmática pode ser utilizada para examinar os dados, identificando o particular como instância de conceitos gerais e localizando os temas comuns ou manifestações conceituais entre as estórias/dados coletados. No entanto, também pode enfatizar a construção ou descoberta de conceitos que dão identidade categórica aos itens em seus dados coletados, assim como para anotar os relacionamentos entre categorias (Bolívar, 2002).

A rede de narrativas é sustentada e transportada através da linguagem local e das experiências individuais. Por isso, Bolívar (2002) indica que é comum a utilização de citações da entrevista, com fins ilustrativos, para apoiar o que previamente se tem determinado em análise quantitativa. Destacamos, por isso, que é importante aproveitar o ponto forte do procedimento paradigmático, que é sua capacidade para desenvolver conhecimento geral sobre uma coleção de estórias e os seus pontos 
comuns. Mas a espécie deste conhecimento, entretanto, é abstrata e formal e não contempla os aspectos únicos e particulares de cada narrativa. Por isso, é necessário complementá-lo com a investigação narrativa.

Tanto Bolívar (2002) quanto Polkinghorne (1995) demonstram que a preocupação da análise narrativa (propriamente dita) detém-se em colecionar casos individuais não para generalizar cada um sobre uma categoria, mas para efetuar analogias, onde os indivíduos podem ter aspectos similares a outros, ou singulares. Baseia-se em uma narrativa particular, mas com fim de expressar a vida individual de modo autêntico, sem manipular a voz dos participantes.

A investigação paradigmática fragmenta o discurso em elementos codificáveis, mas concordamos com Bolívar (2002) que o investigante não deve só tomar nota e classificar o discurso, ele precisa decifrar significativamente os componentes e dimensões relevantes das vidas dos sujeitos, situando os relatos narrativos em um contexto que tome um sentido mais amplo.

Defendemos que devemos ir além do discurso do entrevistado, sem categorizá-lo a priori, superando a colagem de fragmentos do texto e penetrando no complexo conjunto de símbolos que as pessoas usam para conferir significado ao seu mundo e vida, descrevendo os relatos de forma que obtenha sentido. Há uma frequente crítica de que é insuficiente tanto uma postura "ilustrativa", que se limita a fazer um uso seletivo das palavras dos participantes, ao serviço do que querem mostrar os investigadores, quanto uma postura "hiper-realista", ${ }^{12}$ que trata de dar todo o valor às próprias palavras dos participantes, como se as palavras fossem por si mesmas transparentes.

A forma de se analisar, que possibilita tomar em consideração estes aspectos, seria a investigação narrativa (Bolívar, 2002). Esta metodologia emprega uma espécie de "visão binocular" (uma visão dupla) que, por um lado, contextualiza a realidade interna do informante e, por outro lado, inscreve o relato em um contexto externo que aporte significado e sentido à realidade vivida pelo informante. As experiências devem ser situadas dentro de um conjunto de regularidades sócio-históricas, mas sem desdenhar que o relato de vida é único e singular.

O processo de análise narrativa deve sintetizar um agregado de dados em um conjunto coerente, em lugar de separá-lo por categorias. Os relatos obtidos devem resultar em uma trama argumental que determina quais elementos devem ser incluídos, com que ordem e com que fim.

Entendemos que, em nossa atual conjuntura, a escrita da investigação narrativa joga-se entre não sacralizar os relatos, nem assimilá-los aos modos tradicionais paradigmáticos de conhecer. Bolívar sugere que o próprio texto narrativo não pode deixar de ser narrativo, ou seja, que o estilo de redação deve reorientar as práticas 
convencionais de investigação. Assim, defendemos uma escrita feita pelo investigador dos próprios relatos, mas tentando aproximá-los o máximo possível das falas (adequando-as às normas da escrita, para tornar a leitura mais fluente), revelando não só os pontos comuns nas estórias, mas sim suas diferenças e singularidades.

Não podemos esquecer, reportando-nos aos trabalhos de Polkinghorne e Bolívar, que as duas formas de investigação (narrativa e paradigmática) têm muito a contribuir nas nossas investigações e podem ser complementares. Enfim, como afirmam Bolívar, Domingo e Fernández (2001), estes dois tipos de investigação não são dicotômicos, ambos contribuem para gerar conhecimento e podem se complementar. Eles assumem que a análise narrativa pode não chegar a cobrir alguns interesses da investigação e, assim, pode ser necessária uma análise de dados categorial. Além disso, ignorar que a narrativa é determinada por uma política e que faz parte de um contexto social mais amplo pode exercer uma função conservadora.

Nosso objetivo, então, é propor uma análise enredada, que pode até conter categorias, mas que não as busca acima de tudo, menosprezando as particularidades de cada relato. Polkinghorne (1995) propõe uma investigação narrativa "enredada" ou "estoriada", ${ }^{13}$ que utiliza análise narrativa sem fins de classificação e ordenação. Os eventos e ações são desenhados em um inteiro organizado pelos significados de um enredo, que é um esquema conceitual pelo qual o significado contextual dos eventos individuais pode ser exibido.

O estudo do enredo possibilita compreender a estrutura narrativa através da qual as pessoas entendem e descrevem os relacionamentos entre os eventos e escolhas de suas vidas, o intervalo temporal, a criação de critérios para selecionar eventos a serem incluídos na estória (ou até os acontecimentos externos que possam contextualizá-la), ordenando os eventos até culminar numa conclusão. Nas estórias recolhidas as pessoas tentam dar um seguimento temporal linear, pois presumem que esta é a forma como o tempo se apresenta (nossa aprendizagem histórica geralmente nos leva a pensar desta forma) e oferece sentido à sua estória (Polkinghorne, 1995).

Dessa maneira, a tarefa do investigador é primeiramente configurar os elementos em uma estória que une e dá significado aos dados. Depois, requer-se uma tarefa analítica para desenvolver ou descobrir um enredo que demonstra a ligação entre os elementos, o que culmina na solução da estória.

Clandinin e Connelly (1991) consideram que a análise narrativa produz uma estória que não pertence a um indivíduo. Ela demonstra o encontro de duas narrativas, do participante e do investigante, que se tornam, em parte, uma construção narrativa partilhada e reconstruída através da investigação. Durante a "contagem e recontagem", o emaranhado de relatos torna-se agudo e os horizontes temporais, sociais e culturais são fixados e re-fixados. 
A este propósito, salientamos que não há como o investigador fugir de adicionar a sua própria voz no processo de pesquisa, indagando sobre o motivo da narrativa ter sido dita de determinada forma. Respondendo a estes questionamentos, os participantes podem penetrar mais profundamente em outras experiências para traçar a "emocionalidade" anexada à sua forma particular de estoriar eventos.

A experiência humana tem uma qualidade estoriada que só pode ser interpretada de maneira qualitativa, pois cada indivíduo descreve narrativamente a sua vivência passada (como criança, docente, investigador ou componente de certo grupo), sempre reanalisando dentro do seu contexto atual - profissional, histórico, social.

A interação entre investigante e praticante guia um contar e recontar mútuo e colaborativo. Isso permite entender a mudança em suas práticas. O "praticante participante" e o "investigante participante" têm diferentes objetivos na investigação narrativa, que se apresentam na sua ampla narrativa social. O praticante expressa seu reestoriar nas relações redivididas no seu contexto de trabalho. O investigante quer reestoriar a sua prática e a sua narrativa, mas também quer recontar a narrativa com o objetivo da sua estória ser lida pelos outros, necessitando igualmente de desenvolver construções teóricas (Clandinin \& Connelly, 1991).

Portanto, como investigantes, objetivamos uma maior audiência dos relatos e necessitamos que esta investigação narrativa seja partilhada. Os relatos narrativos podem ser vistos por outrem como narrações de suas próprias estórias, que, esperamos, possam suscitar nos leitores uma vontade de recontar/rever as suas próprias estórias e indagações sobre a prática.

Mas não precisamos somente que o nosso texto seja partilhado. Como investigadores, necessitamos tanto de construções teóricas como da narrativa estoriada e, por isso, escolhemos os dados que serão recolhidos dependendo do foco da nossa investigação. Isso pressupõe uma delimitação de estudo que deve entrelaçar os relatos individuais (que providenciam um entendimento das idiossincrasias e complexidades particulares), mas de modo que nem todos os dados precisem constar no relato final da estória (pois nem sempre são necessários para o enredo).

As ponderações de Polkinghorne (1995) guiam-nos neste processo e consideram a análise de dados narrativos como um procedimento através do qual o investigante organiza os elementos em um relato coerentemente desenvolvido, sintetizando os dados em vez de separá-los em suas partes constituintes. O autor adverte-nos que a análise de dados narrativos não está presente em todo tratamento de dados, mas somente quando o investigante configura os elementos em um inteiro coerente.

Enfim, para tentar contornar as dúvidas, que são as marcas de qualquer investigação social expressiva, é imprescindível considerar as questões práticas. Isso pressupõe que estudar como as pessoas "narrativizam" a experiência necessita de 
técnicas de pesquisa mais cuidadosas para não suprimir ou cortar os entrevistados, quando eles "desatam a contar histórias". Dessa forma, intensificam-se não só os cuidados, mas a busca das bases narrativas para as investigações.

A prática está presente na construção narrativa, na sua concepção como experiência pessoal temporal. Por isso, devemos considerar que, ao narrar, um indivíduo encontra-se em um processo de recriação de "si mesmo", um processo que visualiza o passado frente às perspectivas presentes, mas organizando-se para o futuro.

\section{A investigação narrativa na educação: enfatizando o quotidiano escolar}

A análise narrativa insere-se nos campos de investigação educacional com grande força, por possibilitar a compreensão das práticas, motivações e escolhas que são amplamente calcadas na experiência humana. A escola, como instituição, está cheia de complexidade, tendo sua base construída no seio das instituições sociais, mas sendo composta por indivíduos que contribuem para a continuidade da mesma. É preciso entender as escolhas pessoais para poder compreender mais acerca da escola e da atividade educacional.

As narrativas apresentam-se como possibilitadoras de um conhecimento mais amplo do professorado e da escola. Até porque, como lembram Bolívar, Domingo e Fernández (2001), o relato constitui a matéria mesmo do ensino, dentro do qual o trabalho dos mestres adquire sentido, o conhecimento do professor se apresenta organizado narrativamente. Eles são contadores de histórias e o território do conhecimento profissional está construído narrativamente. Assim, nos aproximamos do seu quotidiano ao empregar este artifício tão comum à sua experiência diária, que libera o conhecimento dos seus aspectos emotivos, que são inseparáveis da sua forma de trabalho.

Bolívar, Domingo e Fernández (op. cit.) expõem que a investigação narrativa permite entender como os docentes dão sentido ao seu trabalho e como atuam em seus contextos profissionais, como o professorado constrói seu saber profissional e como a reflexão que é colocada pela narrativa pode ser (ela mesma) formativa. A narração da experiência é o modo como o docente integra sua teoria e prática de ensino. Portanto, contar e recontar a sua experiência são uma boa estratégia para refletir sobre sua própria identidade e para "desidentificar-se" de práticas já realizadas ou antecipar o que se deseja fazer/ser.

Resgatar a dimensão pessoal do ofício de ensinar é um modo de opor-se ao professorado anônimo, sem nome e impessoal. A investigação narrativa é uma forma de dar voz aos professores sobre suas preocupações e suas vidas, supõe uma 
fissura nos modos habituais de compreender e investigar, pois qualquer generalização acerca do ensino significaria uma distorção das histórias reais dos professores, já que os relatos destes não são vídeos que refletem a realidade, são construções (Bolívar, Domingo \& Fernández, 2001).

Bolívar (2002) indica que os relatos docentes são construções sociais que oferecem determinados significados às ações e, dessa maneira, devem ser analisados nas investigações tanto de forma paradigmática, quanto de forma narrativa. As biografias dos professores podem oferecer possíveis explicações do porquê de dizerem o que dizem.

Clandinin e Connelly (1991) percebem que "estoriar e reestoriar" uma vida é um método fundamental de crescimento pessoal, sendo uma qualidade fundamental da educação. Portanto, uma investigação narrativa deve construir-se nesse processo de desenvolvimento, descrevendo e reestoriando a estrutura narrativa da experiência educacional. O relato do investigador deve prender-se neste reestoriar dos eventos, que têm uma dimensão contínua com os processos reflexivos que acontecem em cada uma de nossas vidas escolares.

Os estudos de vida e as narrativas dos professores possibilitam aceder a uma informação de primeira ordem para conhecer de modo mais profundo o processo educativo, um meio para que os professores reflitam sobre sua vida profissional e compreendam, em seus próprios termos ou vozes, como eles mesmos vivem seu trabalho e tomam esta compreensão para mudar o que não gostam no seu trabalho e na sua atuação profissional (idem, ibid.).

No entanto, não podemos esquecer de que precisamos relacionar as narrativas individuais dos professores com um contexto histórico mais amplo, pois cada professor é único e só se pode compreendê-lo desde sua própria trajetória biográfica individual; ao mesmo tempo, cada professor apresenta aspectos comuns dentro de um grupo particular de professores com quem compartilha uma mesma historia; igualmente, cada professor apresenta aspectos gerais compartilhados com os companheiros (de sua geração, do mesmo ciclo de vida etc.). Assim, não basta limitarmo-nos a recolher o que dizem os docentes, pois o narrado está determinado por uma política educativa e curricular, que forma parte de um contexto social mais amplo. Silenciar estes determinantes pode, implicitamente, exercer uma função conservadora, pois santificar a narrativa dos professores pode querer substituir um paradigma dominante por outro, sem alterar a dominação (Bolívar, Domingo \& Fernández, 2001).

A educação não é uma verdade objetiva (em forma de leis empíricas que mostrariam a conexão entre conduta do professor e resultados de aprendizagem dos alunos). Dessa forma, os investigadores da educação não se dirigem a estabelecer o caráter objetivamente verdadeiro dos acontecimentos, buscando verificar o que diz 
o relato, mas a refletir como tem sido vivido subjetivamente pelo sujeito. A tarefa é ajudar os professores a melhorar o que fazem, não prescrever o que têm que fazer (idem, ibid.). Portanto, a investigação narrativa caracteriza-se tanto pela atenção cuidadosa à autoridade interpretativa do investigador, quanto pela relevância da voz do informante. Realizar este tipo de investigação na educação significa um impacto na prática educativa, envolvendo os professores como "sócios" da pesquisa.

As pessoas que investigam a educação estão abandonando gradualmente a busca da "grande verdade", estando cada vez mais satisfeitos com a descrição de processos locais, teorizando acerca de problemas específicos. Propomos que a tarefa da narrativa seja esclarecer os dilemas da prática, que geram os pensamentos. Por conseguinte, não há melhor campo para ela se "alastrar" do que na educação. Pois, ao efetuar um olhar mais detido sobre o seu passado, o professor tem a oportunidade de refazer o seu percurso, ${ }^{14}$ os desdobramentos desta análise revelam-se fecundos para estampar novos significados às experiências passadas e reformular as práticas futuras.

As narrativas escolares apresentam o contexto escolar e podem tentar libertar a pesquisa da coerção narrativa, que marca um só discurso explicador legitimado como correto, deixando de ouvir os outros discursos. Existem muitos desafios da investigação narrativa sobre a escola. Um deles é a necessidade de alargar as unidades de análise para que possamos nos manter próximos da experiência, de quem a vivencia, da língua prática e das vidas dos professores.

\section{Notas}

1. Ao contrário, o indivíduo nasce confuso e se integra no esquadrinhamento disciplinar, emergindose como alvo do poder. Assim ele não é esmagado pelo poder, mas produzido por este.

2. Os autores descrevem a socialização primária como a primeira socialização ocorrida na infância que introduz o individuo não só na sociedade, mas também em determinada localização na sua estrutura social, com escolhas inerentes às suas idiossincrasias individuais. O primeiro mundo do indivíduo é construído neste período de socialização.

3. Nossa competência de alterar o presente, "voltando" ao passado, ou alterar o passado à luz do presente.

4. Um simples evento pode mudar a maneira com que a pessoa descreve sua narrativa.

5. O coletivo vai além do somatório das ações individuais, e as singularidades também são mais do que uma parte da coletividade.

6. Como a entrevista biográfica.

7. Toda investigação qualitativa é também narrativa, de forma ampla, pois seus informes estão cheios de narrativas (Bolívar, Domingo \& Fernández, 2001).

8. Como notas de campo, jornais, cartas, diários, planos de aulas, entrevistas transcritas...

9. Até porque a quantidade de dados gravados/transcritos com que um investigador pode trabalhar é limitada. Assim, o apoio de outras técnicas pode ser importante para melhor compreender um problema.

10. Com um roteiro com perguntas temáticas que estimulam o entrevistado a recontar sua vida. 
11. Como narrativa histórica, estudo de caso, história de vida, episódio narrado da vida de alguém...

12. Ou utopia biográfica, que faz uma mera descrição e renúncia da explicação teórica.

13. A aplicação da palavra "estória", ao invés de "história", não é efetuada pelo autor por esta carregar uma conotação de falsidade, mas para mostrar que a narrativa evidencia uma visão do mundo cultural/ideológica, compreende a complexidade da ação humana, mas também legitima e relativiza valores/objetivos que combinam uma sucessão de incidentes em um episódio unificado (Polkinghorne, 1995, p. 7).

14. Bolívar, Domingo e Fernández (2001) descrevem que a maioria dos relatos constitui-se em torno de sucessos (valorados positiva ou negativamente), as narrativas de professores são cheias de elementos autoavaliativos, adotando uma escala valorativa. A comparação de cada história biográfica de vida possibilita ver padrões concorrentes, temas comuns e divergências nas trajetórias do professorado.

\section{Referências}

BERGER, P.; LUCKMANN, T. A construção social da realidade. Petrópolis: Vozes, 1985.

BOLIVAR BOTIA, A. “¿De nobis ipsis silemus?”: epistemología de la investigación biográfico-narrativa en educación. Revista Electrónica de Investigación Educativa, MéxiCO, DF, v. 4, n. 1, 2002.

BOLIVAR BOTIA, A.; DOMINGO SEGOVIA, J.; FERNÁNDEZ CRUZ, M. La investigación biográfico-narrativa en educación. Madrid: La Muralla, 2001.

BROCKMEIER, J.; HARRÉ, R. Narrativa: problemas e promessas de um paradigma alternativo. Psicologia: Reflexão e Crítica, Porto Alegre, n. 16 (3), p. 525-535, 2003.

BRUNER, J. Actual minds, possible worlds. Cambridge: Harvard University, 1986.

BRUNER, J. Actos de significado: para uma psicologia cultural. Lisboa: Edições 70, 1990.

CLANDININ, D.J.; CONNELLY, F.M. Narrative and story in practice and research. In: ScнöN, D.A. (Ed.). The reflective turn: case studies in and on educacional practice. New York: Teachers College, 1991. p. 258-281.

FOUCAULT, M. Microfísica do poder. Rio de Janeiro: Graal, 1979.

GUDMUNDSDÓTTIR, S. Narrative research on school practice. In: RICHARDSon, V. (Ed.). Fourth handbook for research on teaching. New York: Macmillan, 2001. p. 226-240.

LYOTARD, J.-F. A condição pós-moderna. 2. ed. Lisboa: Gradiva, 1989.

POLKINGHORNE, D.E. Narrative knowing and the human sciences. New York: State University of New York, 1988. 
A importância da investigação narrativa na educação

POLKINGHORNE, D.E. Narrative configuration in qualitative analysis. In: $\mathrm{HATCH}_{\text {, }}$ J.A.; WISNIEwsKI, E.R. (Ed.). Life history and narrative. London: Falmer, 1995. p. 5-23.

Recebido em dezembro de 2008.

Aprovado em setembro de 2009. 